gests that the changes with age are lung volume dependent, which possibly alters the properties of the respiratory muscles. Whether neural recruitment of intercostal muscles is important to explain the increased $E^{\prime}{ }_{k s}$ in preterm infants remains unknown. Neural recruitment seems important in animals and is probably vagally mediated $(4,6)$.

The $\mathrm{E}_{\mathrm{R} \text { s }}^{\prime}$ has been used as an index of ventilatory stability (4$6)$. Increased $E_{R S}^{\prime}$, reflecting high impedance of the respiratory system, would increase the stability of the tidal volume when the system is presented with external elastic loads (4-6). Exactly what benefit the preterm infant might derive from this increased $E^{\prime}{ }_{k s}$ is questionable. Loads imposed during feeding, by change in position, or by partial nasal obstruction may be "physiologically adapted" to body size and may not require more of a compensatory mechanism in preterm than in term infants. Preterm infants do have a higher pulmonary impedance than term infants, probably because of their morphologically immature lungs, with increased interstitial/air space ratio (12). This high pulmonary impedance coupled with an unusually compliant chest wall may represent an unstable compromise as compared to the term infant, with a low pulmonary impedance and a stiffer chest wall. At least, if regular breathing is taken as an index of good respiratory stability, preterm infants have little or no stability (11).

\section{CONCLUSION}

We suggest that the increased $E^{\prime}{ }_{\text {sis }}$ observed in preterm infants is lung volume dependent. This maty alter the intrinsic properties of the respiratory muscles, by altering the geometry of the thorax and eventually the force/length characteristics of these muscles. We further suggest that this increased $E^{\prime}{ }_{\text {tes }}$, despite being accepted traditionally as an index of increased ventilatory stability, is not of much benefit to preterm infants who have the most unstable respiration at a time when $E_{n s}^{\prime}$ is maximum. Finally, if $E^{\prime}{ }_{k s}$ is an index of mechanical stability of the respiratory system, the inference would be that periodic breathing and apnea seen in preterm infants are independent of the mechanical properties of the respiratory system.

\section{REFERENCES AND NOTES}

1. Adler, S. M., Thach. B. T., and Frantz, I. D.: Ventilatory stability of the premature infant. Pediat. Res., 9: 393 (1975).

2. Bryan, A. C.: Personal communication.

3. Fenner, A., Schalk, U., Hoenicke, H., Wendenburg, A., and Rochling, T.: Periodic breathing in premature and neonatal babies: Incidence, breathing pattern, respiratory gas tensions, response to changes in the composition of ambient air. Pediat. Res., 7: 174 (1973).

4. Krauss, A. N., and Auld, P. A. M1.: Pulmonary gas trapping in premature infants. Pediat. Res. 5: 10 (1971).

5. Lynne-Davies, P., Couture, J., Pengelly, L. D., and Milic-Emili, J.: Immediate ventilatory response to added inspiratory elastic loads in cats. J. Appl. Physiol., 30: 512 (1971).

6. I.ynne-Davies, P., Couture, J., Pengelly, L. D., West, D., Bromage, P. R. and Milic-Emili, J.: Partitioning of immediate ventilatory stability to added clastic loads in cats. J. Appl. Physiol., 30: 814 (1971).

7. Mead, J.: Mechanical factors in breathing. In: J. B. L. Howell and E. J. M. Campbell: Breathlessness, p. 139 (Blackwell, Oxford, 1966).

8. Nelson, N. M., Prodhom, L. S., Cherry, R. B., Lipsitz, P. J., and Smith, C. A.: Pulmonary function in the newborn infant. V. Trapped gas in the normal infant's lung. J. Clin. Invest.. 42: 1850 (1963).

9. Olinsky, A., Bryan, M. H., and Bryan, A. C.: Response of newborn infants to added respiratory loads. J. Appl. Physiol., 37: 190 (1974).

10. Rigatto, H., and Brady, J. P.: A new nosepiece for measuring ventilation in preterm infants. J. Appl. Physiol., 32: 423 (1972).

11. Rigatto, H.. and Brady, J. P.: Periodic breathing and apnea in preterm infants. I. Evidence of hypoventilation possibly due to central respiratory depression. Pediatrics, 50: 202 (1972).

12. Thurlbeck, W. M.: Postnatal growth and development of the lung. Amer. Rev. Resp. Dis., 111: 803 (1975).

13. This research was supported by Medical Research Council of Canada Grant MA-4980 and The Children's Hospital of Winnipeg Research Foundation, Inc.

14. We are grateful to Dr. V. Chernick for comments and criticisms, and to Mrs. $M$. Szajcz for typing and helping in the preparation of the manuscript.

15. Requests for reprints should be addressed to: H. Rigatto, M.D., Department of Paediatrics, Women's Centre, 700 William Ave., Winnipeg, Manitoba R3E OZ3 (Canada).

16. Received for publication May 4,1976

17. Accepted for publication December 1,1976

\title{
The Effect of Maternal Starvation on the Metabolic Response to Cold of the Newborn Rabbit
}

\author{
J. L. IEDSON'"1"' AND D. HUI.L. \\ Department of Child Health, University Hospital and Medical School, Nottingham, England
}

\section{Summary}

Acute starvation of the pregnant rabbit before delivery leads to lipid mobilization, the circulating concentrations of free fatty acids (FFA) increase, and more fatty acids cross the placenta and are stored as triglyceride in fetal tissues, particularly the liver and adipose tissue. Thus the newborns from these unfed does are born with larger fat stores than normal.

In this investigation the responses of newborns of unfed and fed does were compared with respect to aspects of the metabolic responses to birth and subsequent cold exposure. It was found that at $2 \mathrm{hr}$ of age the newborns of unfed does had higher circulating concentrations of FFA and triglycerides. The glucose and glycerol concentrations were similar in the two groups, but after $2 \mathrm{hr}$ of cold exposure the newborns of fed does had much higher blood concentrations of both glucose and glycerol. In both, a large increase in FFA concentration was seen. The newborns of unfed and fed does had similar minimal metabolic rates, 
but the maximal rate of heat production was greater on average by $15 \%$ in the newborns of unfed does over the first 3 days of life.

Maternal nutrition immediately before delivery has considerable effect on the circulating concentrations of metabolites and the reponses to cold of the newborn.

\section{Speculation}

In experimental animals and man it has been shown that maternal blood concentrations of free fatty acids influence the net flux of fatty acids to the fetus. The effect of maternal starvation immediately before birth leads to an increase in fetal lipid stores. Newborns from a starved mother might be expected to respond differently with respect to mobilization of energy reserves when they experience starvation and cold exposure for the first time. Newborn rabbits of unfed does had similar blood concentrations of glucose but higher concentrations of FFA and triglycerides than usual; they also had a better thermogenic response to cold. In this regard they seem better able to withstand acute cold exposure and starvation. A mother's reluctance to eat immediately before delivery may well benefit her young and these advantages may be reduced by such measures as intravenous glucose feeding.

If the pregnant doe rabbit is not fed for $48 \mathrm{hr}$, her circulating concentrations of glucose fall and those of free fatty acids double (1). One consequence of the rise of maternal FFA circulating concentrations is an increase in the flux of fatty acid from the maternal circulation through the placenta to the fetus (3). The fetal fat stores in the liver and adipose tissue increase (1). These experiments were designed to investigate whether or not this experience before birth had any effect on the newborn's responses after birth, in particular in their metabolic responses to cold exposure.

\section{METHODS}

The rabbits, New Zcaland White/Californian crossbreed, were kept under known controlled ambient conditions in the animal house. They were mated at known times, and delivered during the morning 31 days from the day of mating. The unfed group of rabbits had their food withdrawn on day 29 of pregnancy, but water was allowed ad libitum.

Two series of experiments were performed, and in both the rabbits were allowed to deliver naturally. In the first series of experiments the young were taken from the mother immediately after she had delivered and placed in an incubator maintained at $36^{\circ} \pm 1^{\circ}$. These rabbits were not investigated until $2 \mathrm{hr}$ after birth so they could adjust to extrauterine life. After the 2-hr period one or two of the young were killed and blood collected by decapitation and all but one of the remainder of the litter were transferred to another incubator at $25^{\circ} \pm 1^{\circ}$. One hour later $50 \%$ of the number of young placed at $25^{\circ}$ were killed and blood collected by decapitation; the remainder were killed after the second hour. Blood was also collected from the rabbit left at $36^{\circ}$. All blood samples were analyzed for blood glucose (8), free fatty acids (2) and glycerol were by the micro-method of Bochringer (measured by biochemical test combination), and triglycerides after saponification were estimated by the glycerol method.

In the second series the rabbits were left with the mother for a short time after delivery to allow them to suckle. They were then weighed and placed in incubators at $36^{\circ} \pm 1^{\circ}$. Feeding was once daily (which is normal for newborn rabbits) by returning them to the nest in the mother's cage. A warm environment was thus maintained, except for $15 \mathrm{~min}$ daily while newborn rabbits were being fed. Only rabbits which had fed well were used for oxygen consumption experiments. Measurements were made for the first 4 days of life.

The rate of oxygen consumption was measured by placing the rabbit in a Perspex chamber, which was part of a closed circuit including a circulating pump (2-3 liters/min) and a soda lime tube to remove the $\mathrm{CO}_{2}$. The Perspex chamber and soda lime tube were immersed in a water bath, the temperature of which was maintained within $0.1^{\circ}$. The oxygen added to maintain the volume of the circuit was measured using a spirometer and is expressed as dry gas at standard temperature and pressure.

The rate of oxygen consumption at different environmental temperatures (day 0 at $35^{\circ}, 30^{\circ}, 25^{\circ}$, and $20^{\circ}$ and days 1,2 , and 3 at $35^{\circ}, 30^{\circ}, 25^{\circ}, 20^{\circ}, 15^{\circ}$ ) was measured for each rabbit. Time was allowed for the rabbit to adjust and the system to equilibrate to each change in environmental temperature and the rate of oxygen consumption was measured for at least $30 \mathrm{~min}$ while in the steady state.

\section{RESULTS}

The newborn rabbits were kept warm at $36^{\circ}$ for at least $2 \mathrm{hr}$ after birth to allow them to adjust to independent existence. There were no differences in the newborn of fed and unfed mothers with respect to their body weights, their metabolic rates at an ambient temperature of $36^{\circ}$ (thermoneutral) (Fig. 1), or the circulating concentration of glucose and glycerol (Fig. 2). However, the circulating concentration of FFA was less in the newborns than in the fed does, a finding consistent with the differences found when fetal blood was collected. There were much lower blood concentrations of triglycerides in the newborns of fed does (Fig. 2).

Cold exposure led to increases in the rate of oxygen consumption of the newborn rabbits over the first 4 days of life on a similar order to that reported previously (5). However, there was a significant difference in the maximum rate achieved depending on whether or not the does had been fed or not prior to delivery (Fig. 1). The newborns from fed does had a thermogenic response which was, on average, $16 \%$ less on day $0,16 \%$ less on day 1 , and $10 \%$ less on day 2 . The difference was not significant on day 3 .

The circulating concentrations of glucose, glycerol, FFA, and triglycerides after $2 \mathrm{hr}$ of cold exposure in the first few hours of life are shown in Figure 2. Cold exposure stimulated a significantly greater rise in the concentration of glucose and glycerol in the newborns of fed does, a similar increase in fatty acid concentration, and no change in triglyceride levels.

\section{DISCUSSION}

These experiments demonstrate that the nutrition of the doe rabbit immediately before delivery has a number of important effects on the metabolic responses of her newborn.

First, the newborn of the unfed does had higher circulating free fatty acid concentrations and higher triglyceride levels. In previous experiments it has been shown that one of the consequences of maternal starvation is a rise in the maternal circulating concentration of free fatty acids, an increase in the umbilical venous-arterial difference in FFA concentrations, and an increase in the fat content of the fetal liver and adipose tissues (1. $3,4)$. The increased cord triglyceride concentrations are probably secondary to the increased FFA concentrations and fetal liver fat content. Cord triglycerides have been measured to evaluate their use as a screening procedure for inherited triglyceridemias in man (9). These present studies suggest that the concentrations in the blood in the immediate newborn period will be considerably influenced by the fetal exposure to maternal nutrients in the days prior to birth.

The second interesting difference between the young of fed and unfed does is the magnitude in the change in glucose concentrations on cold exposure. The newborn of fed does on cold exposure had much higher glucose concentrations than the newborn of unfed does. These differences might be due to increased mobilization of glucose by the newborn of fed does or an increased rate of uptake by peripheral tissues, and, in particular. 


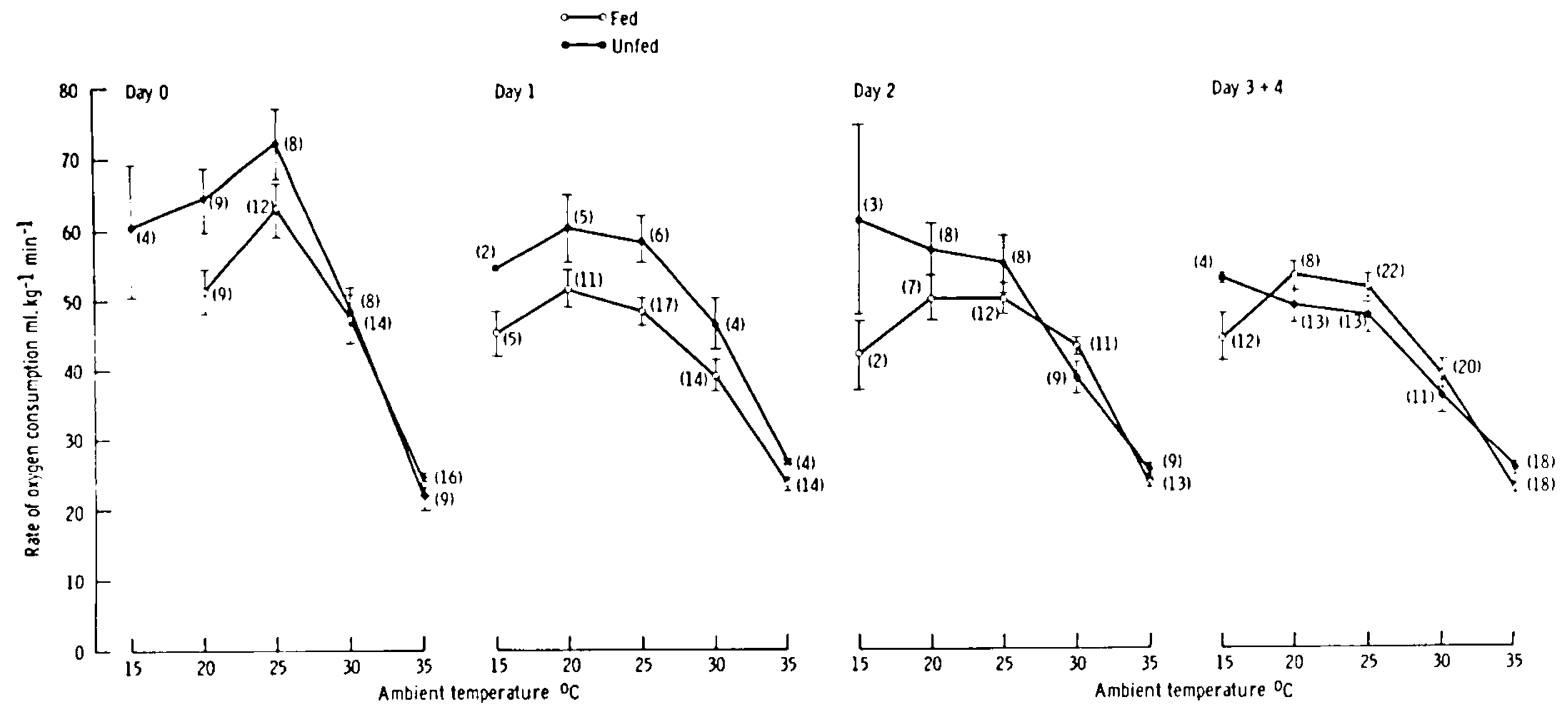

Fig. 1. The oxygen consumption per $\mathrm{kg}$ body weight per min for newborn rabbits at different ambient temperatures in young from normal fed mothers $(O)$ and in young from mothers fasted for $48 \mathrm{hr}$ prior to delivery $(\bullet)$. The symbol represents the mean value of the number of measurements shown in brackets; the vertical line is the SE of the mean.
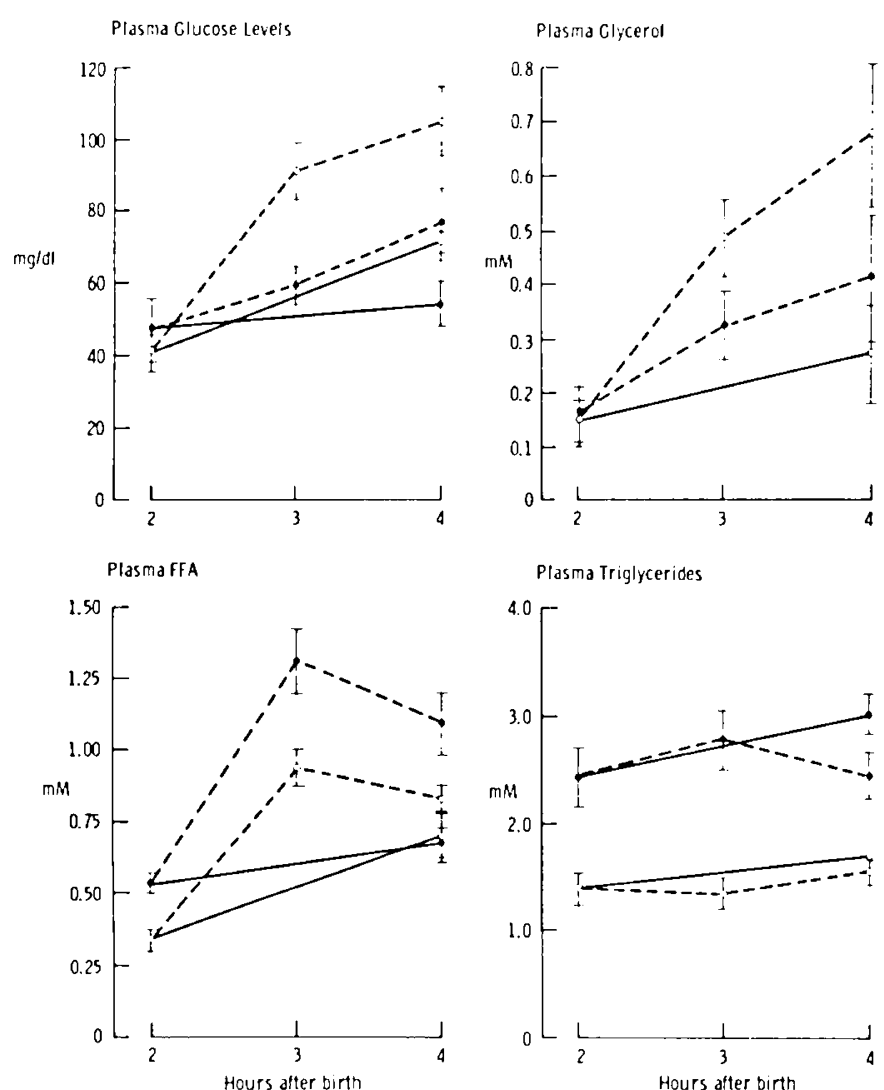

Fig. 2. Changes in blood glucose, serum free fatty acids, glycerol, and triglyceride concentrations during cold exposure at $25^{\circ}\left(-{ }_{-}\right)$in unfed newborn rabbits $2 \mathrm{hr}$ after birth from $(O)$ normal fed does and (•) from does fasted $48 \mathrm{hr}$ before delivery. The control newborn rabbits (-) were kept at $36^{\circ}$. Each symbol is the mean of at least six experiments; the vertical line represents the SE of the mean.

the uptake by thermogenic brown adipose tissue by the newborn of unfed does. Both may be among the factors leading to the differences observed.

The third important difference between the two groups of newborns is the magnitude of the thermogenic response to cold as indicated by the difference in the maximal rate of oxygen consumption. There are obviously many factors, including the rates of gaseous exchange in the lungs, the cardiac output, and tissue blood flows, as well as the size and thermogenic capacity of the heat-producing tissues which determine the maximum rate of thermogenesis and thus the ambient temperature range over which the newborn mammal can maintain thermoregulatory control. The newborns from unfed does had a rate of oxygen consumption over the critical first two days of life which wats over $15 \%$ greater than that of newborns from fed does. As the rabbits in the two groups were of similar weight and age, it would seem likely that the difference reflects a difference in the thermogenic capacity of the heat-producing tissue. In the newborn rabbit this is principally brown adipose tissue (6). In previous experiments it was shown that one consequence of maternal starvation was an increase in the fat content of adipose tissue (1). This, in itself, does not explain the increase in thermogenic capacity for the maximal rate of heat production appears to be independent of the tissue fat content unless the animal's total body stores are critically and severely depleted (7). The answer presumably lies in the controlling hormone system. Sympathetic nervous activity, circulating catecholamines, glucagon, corticotrophin, and thyroxin all influence the rates of thermogenesis in brown adipose tissue of the newborn.

\section{REFERENCES AND NOTES}

1. Edson, J. L., Hudson, D. G., and Hull, D.: Evidence of increased fatty acid transfer across the placenta during a maternal fast in rabbits. Biol. Neonate, 27: 50 (1975).

2. Elphick, M. C.: Automated modification of Duncombe's method for the ultramicro determination of serum free fatty acids. J. Lipid Res., 16: 402 (1975).

3. Elphick, M. C., Hudson, D. G., and Hull, D.: Transfer of fatty acids across the rabbit placenta. J. Physiol., 252: 29) (1975).

4. Elphick, M. C., and Hull, D.: Transfer of individual free fatty acids across the rabbit placenta. J. Physiol. (In press.)

5. Hull, D.: Oxygen consumption and hody temperature of newborn rabhits and kittens exposed to cold. J. Physiol., 177: 192 (1965).

6. Ilull, D., and Segall, M. M.: The contribution of brown adipose tissue to heat production in the newborn rabbit. J. Physiol., 181: 449 (1965).

7. Hull, D., and Segall, M. M.: Sympathetic nervous control of brown adipose tissue and heat production in the neuborn rabbit. J. Physiol., $181: 458$ (196.5).

8. Huggetl, A. St. G., and Nixon, D. A.: Use of glucose oxidase, peroxidase and o-dianisidine in determination of blood and urinary glucose. Lancet, $i i$ $368(1957)$.

9. Tsang, R. C., Glucck, C. J., Evans, G., and Stemir, P. M.: Cord bleod hypertriglyceridemia. Amer. J. Dis. Child., 127: 78-82 (1974).

10. Requests for reprints should be addressed to: J. L. Edson, Deparment of Child Health, University Hospital and Medical School, Nottingham NG7 2 UI1 (England).

11. Received for publication October 22, 1976

12. Accepted for publication December 9, 1976 